\title{
The Structure and Mechanical Properties of Low Carbon Steel after Controlled Rolling and Low-Temperature Treatment
}

\section{P.O. Selivanov, V.A. Khotinov, and O.V. Selivanova}

B. N. Yeltsin Ural Federal University, 19 Mira St., Ekaterinburg, Russian Federation

\section{Abstract}

The structure and mechanical properties complex of $X 80$ pipe grade steel after controlled rolling and low-temperature treatment were studied.

The microstructure of $X 80$ pipe steel has been studied, the size of the structural components has been determined. The mechanical properties of steel for samples cut perpendicular and parallel to the direction of the rolling axis are determined. Serial curves of impact toughness were constructed and the fracture surfaces of the samples of the steel under investigation were researched.

Corresponding Author:

O.V. Selivanova

sov23@mail.ru

Received: 25 February 2019

Accepted: 9 April 2019

Published: 15 April 2019

Publishing services provided by

Knowledge E

(c) P.O. Selivanov et al. This

article is distributed under the

terms of the Creative Commons

Attribution License, which

permits unrestricted use and

redistribution provided that the

original author and source are

credited.

Selection and Peer-review under the responsibility of The Ural school-seminar of metal scientists-young researchers Conference Committee.
Keywords: ferrite, controlled rolling, accelerated cooling, bainite, macrostructural analysis, impact toughness, low-temperature annealing

\section{Intorduction}

Development of high strength steels for the new generation of gas pipelines designed for a high operation pressure is subject of many studies in pipeline and pipe making industries. The guarantee of shear fracture arrest is one of main issues. Steady increase of technical requirements to a wide complex of mechanical properties determining reliability of a pipeline has resulted in essential achievements in V, Nb, Ti-microalloyed low and extra-low carbon pipeline steels. Secondary refining and continuous casting followed by thermo-mechanical controlled processing (TMCP) with strict temperaturereduction route and post-deformation cooling rate control are used to produce $X 80$ and a higher grade pipes [1-3].

Depending on the composition and parameters of TMCP the microstructure of pipeline steel consists of polygonal ferrite, quasi- polygonal ferrite, pearlite, bainitic ferrite, martensite. Mechanical properties of steel after controlled rolling depend on

\section{G OPEN ACCESS} grain size, phase fraction, precipitates and texture [4]. 
During the pipe making process, cold forming (with a strain of about 1\%), followed by anti-corrosion coating at around $250^{\circ} \mathrm{C}$, is essentially a static strain aging process, which will generally increase strength and decrease ductility.

One of method to protect pipes from corrosion damages, is to apply a thicker external coating, such as a fusion bond epoxy coating [5]. During the coating process, the pipes are heated up to the temperature range in which the coating materials melt. Strain aging of the pipe incurred during coating heating could increase the yield strength of the pipe to some degree. This, in turn, increases the yield ratio $(\mathrm{Y} / \mathrm{T})$ and possibly worsens the deformability of the pipes [6].

\section{Experimental}

The chemical composition of the steel under investigation, expressed in wt.\%, was

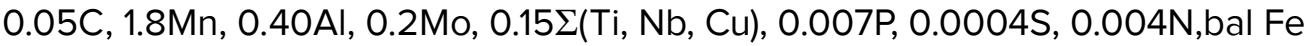

The samples of low carbon pipeline steel were investigated after controlled rolling and low-temperature annealing $\left(t=250^{\circ} \mathrm{C}\right)$. The structure of the steel was studied by optical microscopy in the direction parallel and perpendicular to the rolling axis.

Specimens for tensile and impact tests were prepared from the rolled sheet in longitudinal and transverse direction. Tensile tests were carried out at room temperature using a universal testing machine INSTRON 3382 at a constant crosshead speed of 3 $\mathrm{mm} / \mathrm{min}$. Charpy V-notch specimens were tested in the temperature range from -40 to $-160^{\circ} \mathrm{C}$

\section{Results and Discussion}

By means of optical microscopy it was found that the structure of the steel consisted of ferrite grains and bainite/martensite (Fig.1). In the orientation perpendicular to the rolling direction, the size distribution of ferritic grains was bimodal with peaks in the region of 2 and $6 \mu \mathrm{m}$. In a direction parallel to the pipe axis, the distribution was close to normal with a peak in the region of $5 \mu \mathrm{m}$.

Fig. 2 shows the stress-strain curves and Table 1 lists the mechanical properties of the investigated specimens.

The controlled-rolled specimens exhibit a continuous yielding behavior during tensile test, which is mainly attributed to the mobile dislocations formed in the matrix during TMCP. Many dislocation sources come into action at low strain and plastic flow begins 


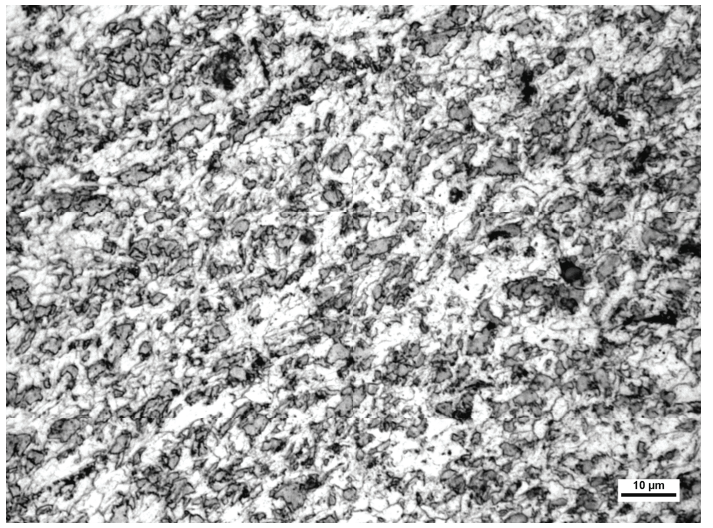

a)

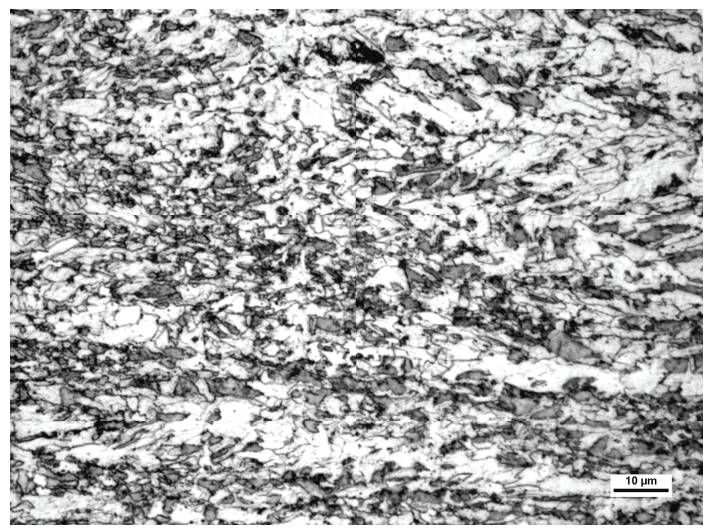

b)

Figure 1: Microstructure of the investigated steel relative to the rolling direction: $a$ - perpendicular; $b-$ parallel.

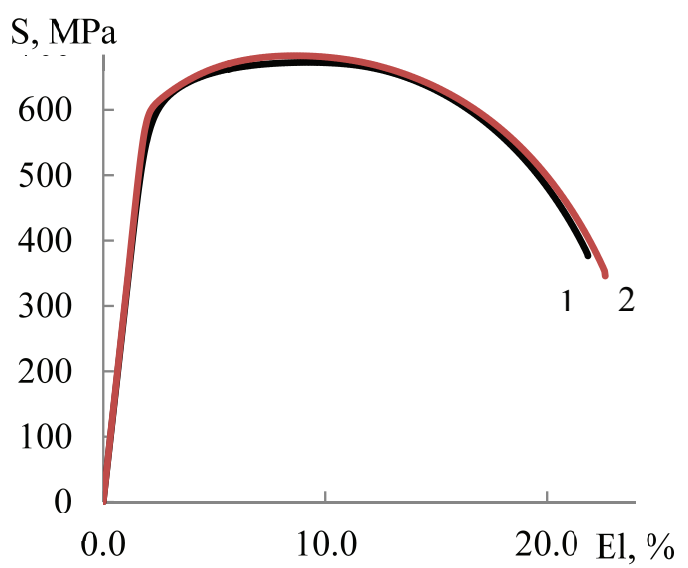

a)

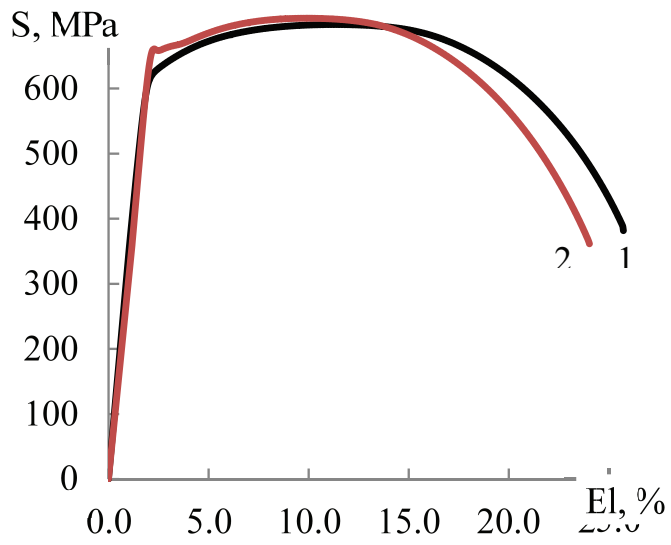

b)

Figure 2: Stress-strain curves of the control rolled (1) and aged specimens cut in the different direction relative to the rolling axis: $a$ - parallel; $b$ - perpendicular.

simultaneously through the specimen, suppressing discontinuous yielding [7]. Aging of sample cut in direction parallel to the rolling axis does not does not influence the stressstrain curve. In contrast, aged specimen cut in direction perpendicular to the rolling axis shows discontinuous yielding, which is a characteristic of strain aging.

As a result of tensile tests, it was found that in the perpendicular direction of rolling, the yield strength was $615 \mathrm{MPa}$, the tensile strength was $700 \mathrm{MPa}$, in the parallel direction is $565 \mathrm{MPa}$ and $670 \mathrm{MPa}$, respectively (Table 1).

Fig. 3 shows the changing in impact toughness with test temperature.

Samples cut parallel to the rolling axis have a higher level toughness compared to samples cut perpendicular to the rolling axis. For example at test temperature $-40^{\circ} \mathrm{C}$ the impact toughness was 3.21 and $2.75 \mathrm{MJ} / \mathrm{m}^{2}$ for samples perpendicular and parallel 
TABLE 1: Mechanical properties of the investigated steel.

\begin{tabular}{l|c|c|c|c|c|c|c|}
$\begin{array}{l}\text { The sample } \\
\text { orientation to } \\
\text { the rolling } \\
\text { direction }\end{array}$ & \multicolumn{1}{|c|}{$\begin{array}{c}\text { Treatment } \\
\text { Parallel }\end{array}$} & $\begin{array}{c}\mathrm{S}_{0,2}(\mathrm{YS}), \\
\mathrm{MPa}\end{array}$ & $\begin{array}{l}\mathrm{UTS}, \\
\mathrm{MPa}\end{array}$ & $\begin{array}{l}\text { Yield } \\
\text { ratio }\end{array}$ & $\mathrm{EL}, \%$ & $\mathrm{RA}, \%$ & $\begin{array}{c}\mathrm{CVN}^{-40} \text {, } \\
\mathrm{MJ}^{2} \mathrm{~m}^{2}\end{array}$ \\
\hline \multirow{2}{*}{ Perpendicular } & TMCP & 565 & 670 & 0,84 & 20,5 & 79 & 3,21 \\
\hline & TMCP + annealing & 600 & 690 & 0,87 & 21,5 & 78 & 4,40 \\
\hline & TMCP & 615 & 700 & 0,88 & 24,5 & 75 & 2,75 \\
\hline & TMCP + annealing & 670 & 715 & 0,94 & 23,0 & 80 & 3,00 \\
\hline
\end{tabular}

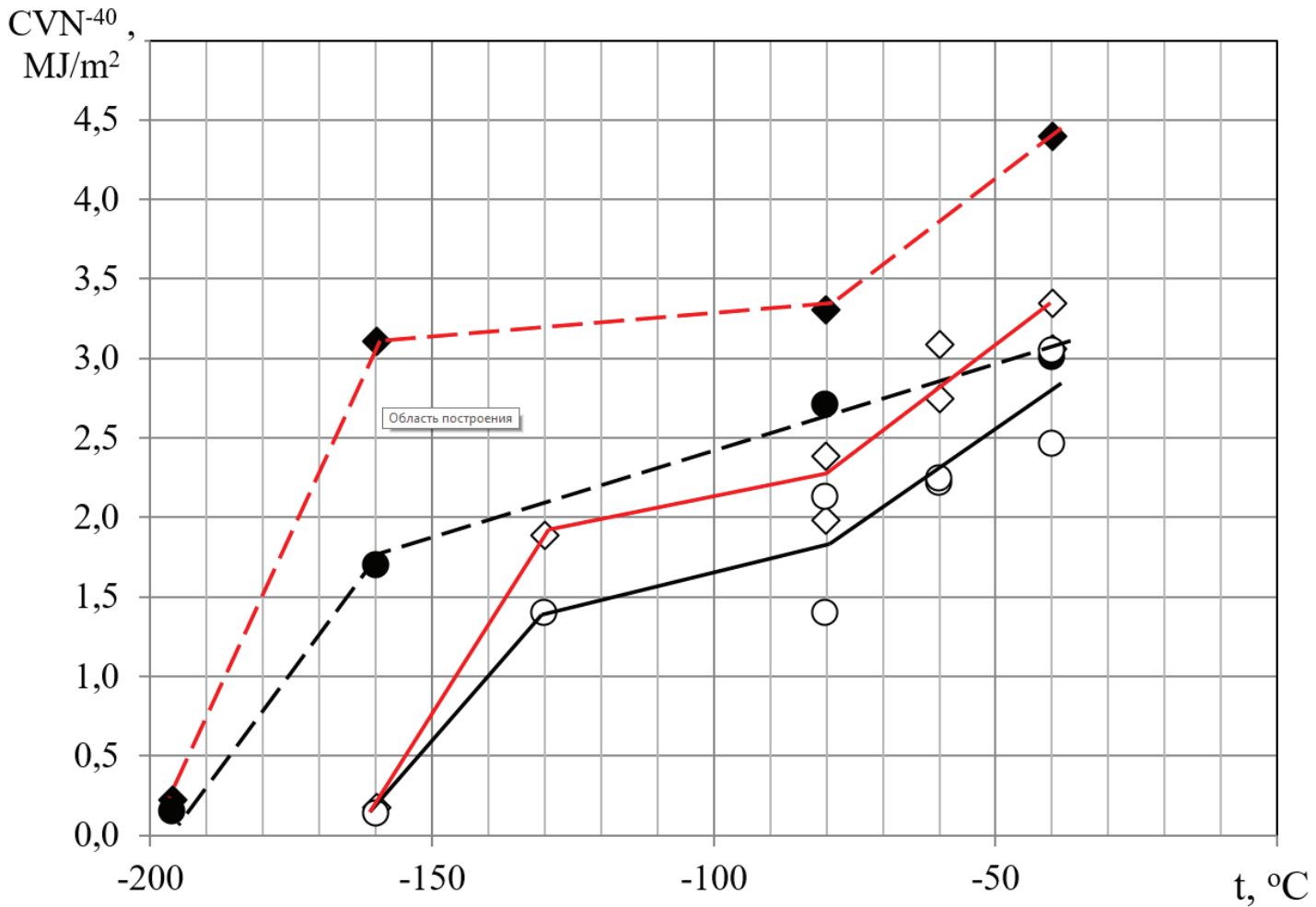

Figure 3: Impact toughness (CVN) of investigated steel after TMCP (white marks) and low- temperature aging (black marks) varying with the test temperature: $\bullet, \bullet-$ perpendicular to the rolling direction, $\diamond, \diamond-$ parallel to the rolling direction.

to the rolling direction, respectively. It can be seen that toughness increases after low temperature aging. The impact toughness level at the test temperature $-160^{\circ} \mathrm{C}$ in the samples cut parallel the rolling direction after low temperature annealing has a high value, namely $3.2 \mathrm{MJ} / \mathrm{m}^{2}$. However, impact toughness at the test temperature $-160^{\circ} \mathrm{C}$ is 0,18 and $0,14 \mathrm{MJ} / \mathrm{m}^{2}$ for samples after TMCP cut parallel and perpendicular to the rolling axis, respectively 


\section{Conclusions}

Low - temperature heat treatment simulated the coating process leads to a noticeable increase of yield stress by $35 \mathrm{MPa}$ in the samples, parallel to the rolling direction, and a slight decrease of yield stress by $6 \mathrm{MPa}$ in the samples perpendicular to the rolling direction. The tensile strength after low-temperature heating increases by $15 . . .19 \mathrm{MPa}$ in samples cut both in the direction parallel and perpendicular to the rolling axis. After low-temperature aging, the tensile stress-strain curves for sample cut perpendicular to the rolling axis show discontinuous yielding behavior.

The elongation was $20.6 \%$ and $21.5 \%$ for samples cut in parallel and perpendicular to the rolling directions, respectively. It is found that low-temperature heating did not significantly affect the plastic properties.

It was found that impact toughness of specimens cut parallel to the rolling direction has the higher values as compared to those for samples cut perpendicular to the rolling direction up to test temperature $-130^{\circ} \mathrm{C}$. Low-temperature annealing of samples leads to an increase in the impact toughness, especially in samples cut parallel to the rolling direction.

The work was carried out using the laboratory equipment "Structural methods of analysis and properties of materials and nanomaterials" of the Center of Ural Federal University.

\section{References}

[1] W. Fazackerley, P. Manuel and L. Christensen: Proc. of Int. Symp. on Microalloyed Steels for the Oil and Gas Industry, (2006), 353.

[2] C. Petersen, K. Corbett, D. Fairchild, Sc. Papka and M. Macia: Proc. of Int. conf. on Pipelines, Ostend, Belgium, (2004), 3.

[3] A. Glover: Proc. of Int. Conf. on Evaluation and Application of High Grade Linepipes in Hostile Environments, Yokohama, Japan, (2002), 33.

[4] R. Shukla, S.K. Ghosh, D. Chakrabarti, S. Chatterjee, Microstructure, texture, property relationship in thermo-mechanically processed ultra-low carbon microalloyed steel for pipeline application, Material Science \& Engineering A 587 (2013) 201-208.

[5] O. Mitsuhiro, S. Nobuo, K. Joe, Development of a High-Deformability Linepipe with resistance to Strain-aged Hardening by HOP (Heat-treatment On-line Process), JFE Technical report No. 12 (Oct. 2008) 
[6] J. Hian, C. Lu, B. Wu, J. Li, H. Li, Innovative analysis of Luders band behavior in pipeline steel, School of Materials and Engineering, Northeastern University, China (2017) 123 $-126$.

[7] V.M. Farber,O.V. Selivanova, O.N. Polukhina, I.Y. Pyshmintsev, A.B. Arabei, Contributions of structural factors to the strength of K65 steels, Steel in Translation. V. 42. № 9 (2012) 687-690. 